\title{
A Decision Framework for the Consolidation of Performance Measurement Systems
}

$$
\text { by }
$$

Laura Grosswiele, Maximilian Röglinger, Bettina Friedl

in: Decision Support Systems 54 (2013) 2, 1016-1029 


\title{
A Decision Framework for the Consolidation of Performance Measurement Systems
}

\author{
Laura Großwiele ${ }^{\mathrm{a}}$ \\ Dr. Maximilian Röglinger ${ }^{\mathrm{a}}$ (corresponding author) \\ Dr. Bettina Friedl ${ }^{\mathrm{a}}$
}

${ }^{a}$ FIM Research Center Finance \& Information Management

University of Augsburg

Universitätsstraße 12

86159 Augsburg

Germany

0049 / $821 / 5984872$

laura.grosswiele@,wiwi.uni-augsburg.de

maximilian.roeglinger@,wiwi.uni-augsburg.de

bettina.friedl@,wiwi.uni-augsburg.de

\begin{abstract}
Numerous performance measurement systems have been expanding over the years. Therefore, they often contain more information than needed as well as irrelevant information. The consequences are high complexity in cognitively processing the enclosed measures and unnecessary costs for operating and maintaining the supporting infrastructure. Against this backdrop, we propose a decision framework that supports the consolidation of existing performance measurement systems such that information processing complexity and costs are balanced with the extent to which decision makers' information requirements are met and alignment with corporate objectives is achieved. We also report on the results of an evaluation based on feature comparison, prototype construction, and a realworld application.
\end{abstract}


Keywords: performance measurement systems, information requirements, decision framework, multicriteria decision analysis, information processing complexity, costs for information provision

\section{Identification of and Motivation for the Research Problem}

Whether for the implementation of corporate strategy, the continuous monitoring of corporate objectives, or the management of business units, performance measurement systems (PMS) are an accepted instrument for providing decision makers with information that enables them to take effective actions [64]. Nevertheless, numerous PMS users indicate that they suffer from information overload $[38,66]$. This is surprising because performance measures and PMS actually are intended to reduce complexity by abstracting from the real world [48]. In particular, PMS that have been subject to uncontrolled growth (i.e., the number of measures they enclose has been increasing over the years) are likely to contain more information than needed as well as irrelevant information. This phenomenon entails challenges for the information provision of decision makers that require intervention.

From an informational perspective, one has to consider the limitations of human information processing capabilities $[17,60,73]$. Cognitively overstrained decision makers suffer from stress and loss of clarity [6], which in turn reduces decision quality [3,20]. As early as 1967, Ackoff recognized that misinformation is not only grounded in too much information, but also in irrelevant, redundant, and heterogeneous information - a problem that has intensified over the last decades $[1,21,28,49]$. Thus, the central challenge from an informational perspective is to answer the question of which measures enclosed in an existing PMS are sufficient to manage the fields of action under investigation at an adequate level of information processing complexity.

From an economic perspective, one has to consider that information provision is not free. The costs of information provision are all too often neglected in the context of PMS [2,41]. A 1999 Hackett Group benchmarking study reported that companies spend an average of more than 25,000 person-days a year per billion dollars of revenue on measuring and reporting performance [34]. This figure may have 
decreased due to a more extensive automation of extraction, transformation, and loading (ETL) procedures, but it nonetheless corroborates the need to investigate PMS from an economic perspective. In doing so, the central challenge is to answer the question of which existing measures and parts of the supporting infrastructure are worth their costs.

While there is an elaborate body of knowledge that deals with the initial design of PMS, very few approaches address the systematic consolidation of PMS (see section 2.3). In the context at hand, consolidation refers to the decision about which measures enclosed in an existing PMS and which parts of the supporting infrastructure should be kept in order to provide sufficient information while at the same time reducing negative informational and economic effects. Against this backdrop, the paper addresses the following research question: How can an existing PMS be consolidated considering the informational and economic challenges of information provision?

To answer the research question, we adopt a design science research approach and propose a decision framework for PMS consolidation as artifact. As the decision framework is a model that enables the comparison of different consolidated PMS and shows characteristics of a method for guiding the process of PMS consolidation, the decision framework is a valid artifact type [55]. In line with existing reference processes for design science research [68], the present work covers the following phases: identification of and motivation for the research problem, objectives of a solution, design and development, and evaluation.

The remainder of this paper is structured as follows: In section 2, we introduce the foundations of PMS to delineate the problem context and unit of analysis. We also extract requirements for useful PMS from the literature that embody the objectives a solution to the problem of PMS consolidation should achieve (objectives of a solution). Using these requirements as an analytical lens, we discuss existing approaches to PMS design and consolidation to identify the research gap. In section 3, we sketch the principles of multi-criteria decision analysis, which serves as the research method for constructing the decision framework presented in section 4 (design and development). Section 5 reports 
on the results of feature comparison, prototype construction, and a real-world application (evaluation). The paper concludes in section 6 with a summary, implications, and limitations.

\section{Domain Background and Related Work}

\subsection{Foundations of Performance Measurement Systems}

Although PMS have been discussed extensively in the international literature on management accounting, operations management, and performance measurement for decades, no common definition has been established so far [25]. Nevertheless, there is a consensus that PMS are an essential instrument of corporate performance measurement, which in turn is a component of performance management at large $[27,67]$. Performance measurement aims to provide decision makers with information that enables them to take effective actions and evaluate whether a company is progressing in line with its strategy. Neely defines performance measurement as "the process of quantifying the efficiency and effectiveness of action" [64].

With respect to what characterizes a PMS, Franco-Santos et al. classified existing definitions into different groups [25]. From an operations perspective, a PMS is a set of interdependent (performance) measures, also known as metrics, figures, or indicators [62]. A PMS also includes the reporting process that gives feedback to employees on the outcome of actions [8]. From a strategic control perspective, PMS include the procedures to translate strategies into measures as well as the systems that provide the necessary information to challenge the content and validity of strategies [39]. From a management accounting perspective, PMS correspond to traditional management planning and budgeting [67]. Franco-Santos et al. concluded that two major features make up a PMS: measures and the supporting infrastructure [25].

Each measure enclosed in a PMS quantifies the efficiency and/or effectiveness of the entity under investigation from a distinct perspective and serves as indicator of overall performance $[9,44,63]$. A comprehensive discussion about the prerequisites for and the drawbacks of using measures as well as about the epistemic underpinnings of measures can be found in Strecker et al. [78]. It is common to 
distinguish between different, though not necessarily disjoint types of measures, such as financial and non-financial measures, leading and lagging measures, measures relating to different perspectives (e.g., financials, customer, business processes, or learning and growth), measures relating to different levels of abstraction (e.g., department-wide, company-wide, or industry-wide), or measures relating to phenomena from inside or outside the company [18,42]. It is important to note that measures in general do not exhaustively cover decision makers' information requirements. They typically have to be complemented by qualitative information such as rumors, press releases, or external reports of competitors. Throughout this paper, we focus on those parts of the information requirements that refer to quantitative information provided by measures.

The performance measurement literature distinguishes between logical, empirical, and hierarchical interdependencies among measures [47,53,65]. Logical interdependencies result from definitions (e.g., profit $=$ revenue - expenses $)$ or mathematical transformation (e.g., return on investment $=$ capital turnover / profit margin). Empirical interdependencies result from observing reality. They are either deterministic or stochastic (e.g., higher prices probably lead to lower sales volume). Hierarchical interdependencies define ranked orders, which can be objective (e.g., annual profit $=$ sum of monthly profits) or subjective (e.g., liquidity is more important than profitability). It is a widespread perception that PMS conform to a tree- or pyramid-like topology where a top measure (e.g., return on investment or economic value added) is decomposed by means of mathematical transformation into an objective hierarchy of lower-level measures. The DuPont System of Financial Control is probably the most popular example. A tree- or pyramid-like topology is feasible if mainly financial and lagging measures are used, and if performance is analyzed at a high level of abstraction. In business practice, however, financial and non-financial measures are used jointly in many cases, as are leading and lagging measures. Moreover, the lower the level of abstraction on which performance is analyzed, the more ambiguous logical and hierarchical interdependencies become. This results in a network-like topology where empirical interdependencies predominate. In practice, empirical interdependencies typically do not meet the requirements of causal relationships and cannot be derived from theoretically valid ex- 
planation models [65]. Rather, they have to be interpreted as "is assumed to indicate" relationships and are stochastic in nature [78]. They can be revealed by analyzing historical data and have to be justified by consulting subject matter experts. Their strength can be quantified by means of measures of coherence as auxiliary quantities (e.g., correlation coefficients or coefficients of determination).

As for the supporting infrastructure of a PMS, there is no common understanding either. It can vary from very simplistic manual methods of recording data to sophisticated information systems and procedures of information provision that involve "data to be acquired, collated, sorted, analyzed, interpreted, and disseminated" [44], including the required human resources [45]. Some authors put the supporting infrastructure and the PMS on the same level (i.e., PMS are interpreted as dedicated information systems with reporting and analysis functionality). Other authors regard the supporting infrastructure as technical and organizational means for implementing the conceptual parts of PMS and facilitating information provision $[13,37,56]$. Independent of the concrete interpretation, it holds true that changes in the measures imply changes in the supporting infrastructure.

With these foundations in mind, we can narrow down how PMS are understood throughout this paper and what consolidation is about. We primarily focus on the conceptual parts of PMS, i.e., the enclosed measures and the interdependencies among them, because it is the measures that convey information to decision makers, not the supporting infrastructure. Without useful content, the infrastructure does not create added value, no matter how sophisticated the IT-based reporting and analysis functionality or the procedures of information provision are. Consequently, the measures enclosed in a PMS should be the starting point for consolidation. We also consider PMS with a network-like topology. This is because such PMS are closer to reality. Consolidation then means that existing PMS come under scrutiny with respect to which of the measures they enclose should be kept. If one intends to incorporate the informational and economic perspectives of PMS consolidation, the effects of changing the measures of a PMS on the supporting infrastructure have to be considered as well. Throughout this paper, we interpret the supporting infrastructure as comprising sophisticated information systems and supporting procedures of information provision used for performance measurement. In the course of 
consolidation, it may happen that parts of the supporting infrastructure can be shut down or need not be executed anymore.

\subsection{Requirements for Performance Measurement Systems}

The literature has not only dealt with the features of PMS, but also with the requirements for a useful PMS. In this section, we compile the requirements for PMS from the literature. These requirements can be used to analyze existing approaches to PMS design and consolidation (see section 2.3), to guide the construction of the decision framework (see section 4), and to evaluate the decision framework (see section 5).

\section{$<<$ Insert Table 1 about here $>>$}

Table 1 provides an overview of seven requirements. Each requirement is presented by means of an identifier, a description, and justificatory references. To extract the requirements, we first analyzed review papers related to PMS and performance measurement. Afterwards, we conducted a backward search for papers with a narrower focus [82]. The results were merged with the results of a general literature search and condensed into requirements. Two researchers performed this process independently to increase reliability [61]. We deliberately chose rather generic descriptions because the requirements should be applicable beyond PMS consolidation, and because we intended to avoid implicitly predetermining a concrete instantiation of the decision framework. Table 1 includes all identified requirements except for "comparability" $[14,31,58]$. This requirement was dropped as we are primarily interested in performance measurement within a single company, not in the comparison of multiple companies.

The requirements are structured along two dimensions: design product vs. design process and informational vs. economic perspective of PMS consolidation. As for the first dimension, requirements (R.1) to (R.4) refer to PMS as design products, whereas (R.5) to (R.7) emphasize the corresponding design process. This is in line with design science research, in which it is common to distinguish between design products and design processes $[33,36,75]$. In our understanding, design refers to both the con- 
struction of new PMS and the consolidation of existing PMS. As for the second dimension, requirements (R.1) to (R.3), (R.5), and (R.6) refer to the informational perspective of PMS consolidation. Requirement (R.4) relates to the economic perspective, and (R.7) is general in nature.

We admit that a certain amount of ambiguity remains: the source papers were heterogeneous, not all papers formulated requirements explicitly, and our requirements are specified prosaically and derived based on our subjective interpretation. Nevertheless, the fact that each requirement is justified by multiple references allows us to infer their appropriateness. We therefore assume that an artifact that addresses these requirements makes a useful contribution to solving the problem of PMS consolidation.

\subsection{Existing Approaches to the Design and Consolidation of Performance Measurement Systems}

According to the previous elaborations, a PMS as a design product and its design process should comply with the outlined requirements. We therefore compare existing approaches using the requirements as an analytical lens to disclose the research gap regarding PMS consolidation.

Existing approaches were identified by means of structured database research based on the following search strategy: Papers had to satisfy the search expression [("performance measurement" OR "performance management”) AND (“design” OR “consolidation” OR “development” OR "evolution”)] for at least one of the search fields of title, abstract, or keywords. The first sub-expression localizes papers in the performance management domain at large. The second sub-expression sharpens the focus with respect to design and consolidation. The following scientific databases served as foundation: ACM Digital Library, AIS Electronic Library, CiteSeerX, EBSCOhost, Google Scholar, IEEEXplore, INFORMS, ProQuest, ScienceDirect, SpringerLink, and Wiley InterScience. We also considered the proceedings of the International and European Conferences on Information Systems. Assuming a cumulative research tradition, the search period was restricted to the years 2000 to 2011. Classifying publications in terms of search fields is a frequently used approach [12], which leads to valid results if based on the previously mentioned search fields and a representative data basis [77]. From the authors' point of view, the data basis at hand is representative. To create a shortlist, each author analyzed the 
identified papers. A paper was sorted out if all authors agreed on its inappropriateness regarding the research question. Table 2 gives an overview on seven approaches to PMS design and consolidation that were identified and examined with respect to the requirements. We discuss the details below.

\section{$<<$ Insert Table 2 about here $>>$}

(R.1) Coverage of the decision makers' information requirements: This requirement is addressed by two approaches. Jensen and Sage [40] proposed iteratively refining an initially compiled PMS until the decision makers' subjective information requirements are met. Neely et al. [62] incorporated a comprehensiveness check where the results of a brainstorming session are validated against a list of predefined areas of interest to ensure that all the important areas for measurement have been covered.

(R.2) Alignment with corporate objectives: All identified approaches postulate that the measures enclosed in a PMS should align with the company's objectives on a corporate level. Three approaches indicate how this could be achieved. Jensen and Sage [40] required measures to be linked qualitatively with subjectively defined objectives. Medori and Steeple [59] proposed deriving measures from predefined success factors. No further recommendations are provided about how this could be done. In the approach of Röglinger [70], each measure is qualitatively attributed to predefined success factors.

(R.3) Adequate information processing complexity: Only the approach of Röglinger [70] explicitly considers the amount of information processing complexity induced by a PMS. In this case, information processing complexity depends on the number of measures enclosed in a PMS.

(R.4) Adequate costs for operations and maintenance of the supporting infrastructure: This requirement is addressed by three papers. Jensen and Sage [40] advised assigning costs for calculation and reporting directly to measures and considering only those measures whose "value" outweighs their costs. No specification is given for the term "value." Neely et al. [62] proposed balancing each measure's costs against its benefits and choosing "high pay-off" measures only. 
They neither indicate how to determine a measure's benefits nor how to determine "high payoff” measures. Röglinger [70] considered present-value payments for customizing and maintaining reporting tools.

(R.5) Consideration of interdependencies among measures: Interdependencies among measures have been considered by Sousa et al. [76] and by Röglinger [70]. The first approach used a systems dynamics approach in a case study setting. The second approach implicitly considered stochastic, empirical interdependencies among measures when addressing the extent to which a PMS satisfies the decision maker's information requirements.

(R.6) Consideration of existing measures: All approaches except that of Bourne et al. [10] consider existing measures during PMS design and consolidation. Jensen and Sage [40] as well as Medori and Steeple [59] suggested designing a PMS based on gap analyses and building on existing structures. To ensure the deletion of redundant measures and the implementation of novel ones, Neely et al. [62] proposed periodic reviews of existing PMS by means of a review checklist. This checklist is not disclosed. Röglinger [70] analyzed an existing PMS and determined the optimal number of measures to which this PMS should be reduced. Wouters and Sportel [83] reported on the results of a case study about the development of a PMS that considers existing performance measures.

(R.7) Systematic involvement of decision makers and subject matter experts: Most of the identified approaches emphasize the participation of future "users" of the PMS and so-called "facilitators" during PMS design and consolidation. Jensen and Sage [40], for example, involved executives as operators of a PMS design tool. Röglinger [70] reverted to subject matter experts to determine the values of input parameters. Three other approaches involve decision makers via different types of group discussions $[10,62,83]$.

The analysis of existing approaches to PMS design and consolidation revealed that each requirement is addressed by at least one approach. No approach, however, meets all requirements in an integrated 
manner. In addition, most approaches are qualitative in nature, which leaves considerable room for ambiguity and causes high manual effort. In our opinion, these arguments make up the overarching research gap. When it comes to single requirements, we feel that each requirement would benefit from additional research. Some requirements seem to be addressed particularly poorly. Bearing the negative consequences of information overload in mind, the fact that an adequate level of information processing complexity (R.3) is considered by only one existing approach motivates fundamental research on how to balance the information processing complexity induced by a PMS against its contribution to satisfying information requirements. With respect to adequate costs for operating and maintaining the supporting infrastructure (R.4), current papers neither reflect nor concretize a measure's or PMS' value, which makes it hard to determine whether a particular PMS justifies its costs. Furthermore, interdependencies among measures (R.5) are barely considered, though they are an important source for identifying redundancies.

Despite this research gap, the existing approaches to PMS design and consolidation provide valuable ideas and solution components to which we will return in section 4. Against this backdrop, we intend to construct a decision framework that builds on existing approaches and contributes to closing the delineated research gap. It shall constitute an integrated and quantitative approach to PMS consolidation and cover the informational and economic perspectives of PMS consolidation.

\section{Research Method}

The decision framework presented in section 4 has been developed in line with the principles of multicriteria decision analysis (MCDA). This is reasonable because the problem of PMS consolidation requires choosing from numerous alternatives based on multiple criteria. MCDA provides assistance in problem structuring, incorporating multiple criteria, resolving conflicts, and the appraisal of value judgments to support a deliberate and justifiable choice among the alternatives $[7,43,71]$. 
Cohon [15] proposed a six-step procedure for solving multi-criteria problems: (1.a) identification and (1.b) quantification of the relevant objectives, (2) definition of decision variables and constraints, (3) data collection, (4) generation and valuation of alternatives based on the mathematical model, (5) selection of the preferred alternative, and (6) implementation of the selected alternative. Steps (1) and (2) are crucial for formulating the underlying mathematical decision model. Hence, they guide the construction of the decision framework. Steps (3) to (6) concern the actual application of the decision framework. We deal with steps (3) to (5) in section 5.4.

The decision framework is developed as follows: First, we outline the general problem setting and derive the objective system from the requirements for PMS as design products as introduced in section 2.2 (step 1.a). This is in line with Cohon, who requires objectives to be identified by searching "published material relative to the decision problem" [15]. Second, we operationalize the objective system by proposing a "statement of each objective as a mathematical function of decision variables" [15] (step 1.b). This step draws from the requirements for the PMS design process outlined in section 2.2, the ideas and solution components of the existing approaches to PMS design and consolidation sketched in section 2.3, and from additional literature. Furthermore, we make non-trivial assumptions that influence the design of the decision framework transparent. These assumptions deliberately abstract from the real world to put a focus on the informational and economic perspective of PMS consolidation. Thereby, decision variables that represent the different consolidated PMS and constraints are formulated (step 2). Finally, the conflicting relationships among the objectives are resolved by integrating the corresponding mathematical functions into an overall objective function [22]. 


\section{Decision Framework for the Consolidation of Performance Measurement Systems}

\subsection{Problem Setting and Objective System}

We consider a company that consists of multiple business units. Each business unit is operated as a profit center and has its own management that makes decisions based on an existing PMS. We focus on a single business unit and introduce the following assumptions and definitions:

(A.1) The existing PMS of the business unit under consideration features a network-like topology. It encloses a set $M=\left\{m_{1}, \ldots, m_{k}\right\}$ of thematically appropriate and metrically scaled measures $m_{i}$ $(1 \leq i \leq k)$. A consolidated PMS $M_{\text {cons }} \subseteq M$ is a subset of the existing PMS.

(A.2) The company's objectives at a corporate level are represented by a single metrically scaled top measure $m_{\mathrm{top}}$.

A measure is thematically appropriate if subject matter experts agree that it can be reasonably used to manage the business unit under consideration. The top measure can be any market-oriented or internal profitability measure, such as earnings before interest or taxes or economic value added [11].

In line with the requirements presented in section 2.2 , the objective system of the decision framework comprises one objective for each requirement for PMS as design products, i.e., (R.1) to (R.4). This is because each consolidated PMS needs to be valuated for the extent to which it satisfies these requirements. As decision makers typically strive for maximization or minimization in mono-criterion optimization settings, (R.1) to (R.4) translate into the following objectives:

(O.1) Maximize the coverage of the involved decision makers' information requirements.

(O.2) Maximize the alignment with the company's objectives at the corporate level.

(O.3) Minimize the information processing complexity.

(O.4) Minimize the costs for operations and maintenance of the supporting infrastructure.

Objectives (O.1) and (O.2) reflect positive informational effects. They tend to increase the number of measures enclosed in the consolidated PMS. Objectives (O.3) and (O.4) cover negative informational 
and economic effects. They tend to reduce the number of measures enclosed in the consolidated PMS. Obviously, the relationships between (O.1) and (O.2) and between (O.3) and (O.4) are complementary. The relationships between $(\mathrm{O} .1)$ and $(\mathrm{O} .3)$ and between $(\mathrm{O} .1)$ and $(\mathrm{O} .4)$ are conflicting. The same holds true for (O.2) and (O.3) and for (O.2) and (O.4). Each objective has to be operationalized to allow integrated valuation of different consolidated PMS.

\subsection{Operationalization of the Objectives}

\subsubsection{Positive Informational Effects}

In this section, we provide the conceptual foundation and a mathematical function for operationalizing objectives (O.1) and (O.2). We treat these objectives simultaneously because both address positive informational effects and because the conceptual foundation of both objectives makes use of stochastic, empirical interdependencies (R.5).

It needs to be considered that the measures of the existing PMS do not in general address all of the decision makers' information requirements. As the decision framework only relies on existing measures (R.6), the best result achievable is that the consolidated PMS provides the same information as the existing PMS. Those parts of the decision makers' information requirements that are not addressed by the existing measures need to be covered by novel measures outside the decision framework. Against this backdrop, we rely on the extent to which a consolidated PMS $M_{\text {cons }}$ covers the information provided by the existing PMS and use the existing PMS as a benchmark in order to operationalize objective (O.1). When determining this extent, we use a direct and an indirect contribution as proxy attributes [70]. The direct contribution results from the fact that the values of the measures enclosed in $M_{\text {cons }}$ are known and can be used directly for decision making. The more measures enclosed in $M_{\text {cons }}$, the higher the direct contribution. The indirect contribution results from the fact that there generally are stochastic, empirical interdependencies among the existing measures. This effect is figuratively referred to as "information overlap" [16]. Thus, the missing direct contribution of nonenclosed measures can be compensated at least partially by indirect contributions based on the inter- 
dependencies among enclosed and non-enclosed measures. As decision makers judge measures as redundant where they expect strong interdependencies, this conceptual idea is corroborated from a business practice perspective [51]. The stronger the interdependencies among enclosed and nonenclosed measures, the higher the information overlap and the indirect contribution. Thus, perfect stochastic interdependencies with non-enclosed measures are treated as being as valuable as if these measures were enclosed [70].

When determining the extent to which a consolidated PMS $M_{\text {cons }}$ aligns with the company's objectives at a corporate level (O.2), we draw an analogy to the concept of indirect contribution because the extent of alignment can be interpreted as the extent of information overlap between the measures enclosed in $M_{\text {cons }}$ and the top measure $m_{\text {top }}$. The stronger the interdependencies among the enclosed measures and $m_{\text {top }}$, the higher the alignment. This is in line with the ideas proposed by Jensen and Sage [40] and Medori and Steeple [59]. It is highly probable that perfect alignment with the objectives at a corporate level is never attained. Some reasons are that the existing PMS does not necessarily contain all relevant drivers of $m_{\mathrm{top}}$, that activities of other business units influence $m_{\mathrm{top}}$, and that interdependencies among the activities of various business units may become manifest as diversification effects.

We make the following assumption for operationalizing objectives (O.1) and (O.2):

(A.3) Between any measures $m_{i}, m_{j} \in M(1 \leq i, j \leq k$ and $i \neq j)$, and between any measure $m_{i} \in M(1 \leq i \leq k)$ and $m_{\mathrm{top}}$, there may exist stochastic, empirical interdependencies that are (statistically) significant and can be justified by subject matter experts. All interdependencies are linear. Their strengths and polarities are constant during the period for which historical data for PMS consolidation is ascertained as well as during the period in which the consolidated PMS is used for decision support.

Linearity simplifies reality. Assuming it is not too restrictive as linear interdependencies are considered sufficient approximation for various economic settings [50,57]. Moreover, measures usually only 
take values from a restricted interval within a relatively short period of time and if the business unit is rather stable. That is, even in the case of non-linear interdependencies, the loss of information due to linear approximation is tolerable if the period of time under consideration is not too long.

As we deal with interdependencies among numerous measures, we draw from the multivariate data analysis body of knowledge [32,35,46,52]. In line with assumption (A.3), we restrict ourselves to multiple linear regression where the strength of interdependency between multiple independent variables and a single dependent variable can be expressed by means of the coefficient of determination $R$ square $\left(R^{2}\right)$. This coefficient represents the fraction of the dependent variable's variance that is explained by the independent variables. If one takes a non-enclosed measure $m_{i} \in M \backslash M_{\text {cons }}$ as a dependent variable and the measures enclosed in $M_{\text {cons }}$ as independent variables, $R^{2}\left(M_{\text {cons }}, m_{i}\right)$ can be interpreted as the extent of indirect information that $M_{\text {cons }}$ provides about $m_{i}$. If one takes $m_{\text {top }}$ as a dependent variable, $R^{2}\left(M_{\text {cons }}, m_{\text {top }}\right)$ represents the extent of alignment with $m_{\text {top }}$. Theoretically, one could also use an adjusted R-square whose value only increases if independent variables with a significant influence on the dependent variable are added to the regression model [35]. The adjusted Rsquare, however, does not conform to the feature of monotonicity, which means that the positive informational effect either increases or remains unaltered if a given PMS is extended by an additional measure. Another reason for using R-square instead of the adjusted R-square is that the decision model covers negative informational effects due to an increased number of enclosed measures by means of objective (O.3).

In order to use multiple linear regression analysis in a methodologically well-founded manner, whether its premises are met has to be checked prior to each application [32,35,52]. A premise worth discussing separately is multicollinearity. While the decision framework focuses on identifying a consolidated PMS whose measures interdepend strongly with the non-enclosed measures and with $m_{\text {top }}$, we cannot exclude the enclosed measures interdepending among one another. Multicollinearity, however, does not constrict the model's validity because we are interested in the contribution of a PMS to covering the information provided by the existing PMS and in the extent to which it aligns with the com- 
pany's corporate objectives. We are not interested in predicting any dependent variable's value or in separating the effects of individual enclosed measures. If a coefficient of determination is insignificant, it nevertheless has to be excluded from further calculations (e.g., by treating it as 0 ).

Based on these considerations, we propose to formalize the positive informational effects (PIE) of a particular consolidated PMS $M_{\text {cons }}$ as follows:

$$
\operatorname{PIE}\left(M_{\text {cons }}\right)=\left[\lambda \cdot \frac{\left|M_{\text {cons }}\right|+\sum_{m_{i} \in M \backslash M_{\text {cons }}} R^{2}\left(M_{\text {cons }}, m_{i}\right)}{|M|}+(1-\lambda) \cdot R^{2}\left(M_{\text {cons }}, m_{\text {top }}\right)\right] \cdot I
$$

where $\lambda \in[0 ; 1]$

is a business unit-specific weighting factor,

$R^{2}\left(M_{\text {cons }}, m_{i}\right) \in[0 ; 1]$ is the coefficient of determination of a multiple linear regression with the measures of $M_{\text {cons }}$ as independent and $m_{i}$ as dependent variables,

$R^{2}\left(M_{\text {cons }}, m_{\text {top }}\right) \in[0 ; 1]$ is the coefficient of determination of a multiple linear regression with the measures of $M_{\text {cons }}$ as independent and $m_{\text {top }}$ as dependent variables, and

$I \in \mathbb{R}^{+} \quad$ is the involved decision makers' subjective monetary equivalent of having all information provided by the existing PMS and perfect alignment with the company's objectives at a corporate level.

Equation $(1)^{1}$ can be interpreted in the order of its components: The first addend within squared brackets quantifies the direct and indirect contributions of $M_{\text {cons }}$ to covering the information provided by the existing PMS. From a regression analysis perspective, the direct contribution can be formalized by the number of measures enclosed in $M_{\text {cons }}$, i.e., $\left|M_{\text {cons }}\right|$. This is because the variance of each enclosed measure is entirely explained by the measure itself. The indirect contribution is based on the stochastic, empirical interdependencies between the measures enclosed in $M_{\text {cons }}$ and the non-enclosed measures $m_{i} \in M \backslash M_{\text {cons }}$. The strengths of these interdependencies are expressed by means of the coef-

${ }^{1} \sum_{m_{i} \in M \backslash M_{\text {cons }}}$ is short for $\sum_{i \in I_{M \backslash M_{\text {cons }}}}$ where $I_{M \backslash M_{\text {cons }}}=\left\{j \in\{1, \ldots, k\} \mid m_{j} \in M \backslash M_{\text {cons }}\right\} ;|\mathrm{X}|=$ number of elements included in X 
ficients of determination $R^{2}\left(M_{\text {cons }}, m_{i}\right)$. To calculate the total indirect contribution, the $\left|M \backslash M_{\text {cons }}\right|$ different $R^{2}\left(M_{\text {cons }}, m_{i}\right)$ values have to be summed up. This sum equals 0 if $M_{\text {cons }}$ encloses no or all existing measures or if all non-enclosed measures are independent of all enclosed measures. It equals $\left|M \backslash M_{\text {cons }}\right|$ if the enclosed measures perfectly interdepend with all non-enclosed measures, which is rather unlikely in real-world settings. Adding the direct and indirect contributions and dividing their sum by the number of existing measures $|M|$ restricts the intermediate result to the interval $[0 ; 1]$. The second addend within squared brackets quantifies the extent of alignment with $m_{\text {top }}$, represented by $R^{2}\left(M_{\text {cons }}, m_{\text {top }}\right)$.

The measures enclosed in two different consolidated PMS generally interdepend to different degrees with the respective non-enclosed measures and $m_{\text {top }}$. That is, while one PMS—say $M_{\text {cons }}^{1}$-may highly cover the information provided by the existing PMS and hardly align with corporate objectives, another consolidated PMS — say $M_{\text {cons }}^{2}$ — may show the opposite properties. The problem of whether to select $M_{\text {cons }}^{1}$ or $M_{\text {cons }}^{2}$ can be resolved by weighting the involved components using a convex combination based on a business unit-specific weighting factor $\lambda$ [43]. The value of $\lambda$ needs to be determined outside the decision framework. A value close to 0 indicates that the involved decision makers attach more importance to managing the business unit in conformance with corporate objectives. A value close to 1 indicates that covering the information provided by the existing PMS is preferred. As both components of equation (1) and $\lambda$ are restricted to the interval $[0 ; 1]$, this holds true for any convex combination as well. The convex combination equals 0 if $M_{\text {cons }}$ encloses no measures. It equals 1 if the measures enclosed in $M_{\text {cons }}$ cover all information provided by the existing PMS and perfectly align with the corporate objectives. Finally, the interim result needs to be monetized to be commensurable with the negative economic effects covered by objective (O.4) (see section 4.2.3). This is achieved by multiplying it with the decision makers' subjective monetary equivalent $I$ of having a PMS that captures the information provided by the existing PMS and that perfectly aligns with the company's objectives. One possibility for determining the value of $I$ involves assessing the decision makers' average willingness to pay for such a PMS $[29,72]$. 


\subsubsection{Negative Informational Effects}

The next objective to be operationalized is (O.3). Before decision makers are able to make decisions based on the measures enclosed in a consolidated PMS, they have to process the provided information. Thus, measures do not only cause positive information effects, but also information processing complexity. We operationalize information processing complexity by means of three proxy attributes. First, information processing complexity depends on the number of measures enclosed in the consolidated PMS $[17,20,80]$. Second, information processing complexity depends on how intuitively each individual enclosed measure can be understood. Third, information processing complexity depends on how heterogeneous are the measures enclosed in a PMS [73].

Based on these considerations, we propose to formalize the negative informational effects (NIE) of a particular consolidated PMS $M_{\text {cons }}$ as follows:

$$
N I E\left(M_{\text {cons }}\right)=\left[\frac{\left|M_{\text {cons }}\right|}{|M|} \cdot \frac{\sum_{m_{i} \in M_{\text {cons }}} e_{i}}{\sum_{m_{i} \in M} e_{i}} \cdot \frac{u_{M_{\text {cons }}}}{u_{M}}\right] \cdot S
$$

where $e_{i} \in\{1, \ldots, n\}, n \in \mathbb{N} \quad$ is the level of individual complexity assigned to $m_{i}$,

$u_{j} \in\{1, \ldots,|M|\} \quad$ is the number of different units within $M_{\text {cons }}$ or $M\left(j \in\left\{M_{\text {cons }}, M\right\}\right)$, and $S \in \mathbb{R}^{+} \quad$ represents the decision makers' subjective monetary equivalent of coping with the information processing complexity caused by $M$

Analogous to the operationalization of objectives (O.1) and (O.2), we use the information processing complexity induced by the existing PMS as a benchmark. Equation (2) can be interpreted in the order of its subcomponents: The first factor within squared brackets quantifies the information processing complexity caused by the number of measures enclosed in $M_{\text {cons }}$ as a fraction of $|M|$. The second factor captures the information processing complexity induced by the individual complexity of each enclosed measure. As a precise determination of the measure-specific complexity is challenging in business practice and may cause an inadequate elicitation effort as well as spurious precision, it seems appropriate to determine each measure's individual complexity approximately and in relation to other 
measures. We suggest defining several levels $(1, \ldots, n)$ of measure-specific complexity [e.g., 1 (simple), 2 (basic), 3 (average), and so forth] and assigning a specific complexity level $e_{i} \in$ $\{1, \ldots, n\}$ to each measure $m_{i} \in M$. To obtain the overall measure-specific complexity, we sum up the complexity levels $e_{i}$ of all measures $m_{i} \in M_{\text {cons }}$ and divide the sum by the respective value for all measures from $M$. The third factor within squared brackets quantifies the information processing complexity caused by the heterogeneity of $M_{\text {cons }}$. We use the number of different units in $M_{\text {cons }}$ to measure its heterogeneity. For example, a PMS that encloses measures expressed in currency unit, piece number, and fraction is more heterogeneous than a PMS whose measures are expressed in a single unit only. Therefore, the number of different units $u_{M_{\text {cons }}}$ featured by the measures enclosed in $M_{\text {cons }}$ is divided by the overall number of different units $u_{M}$ featured by the measures from $M$.

To get an overall understanding of the information provided by a consolidated PMS, not only the enclosed measures, but also the manifold relationships among them have to be processed [79]. Moreover, it has to be considered that human information processing capabilities are limited $[17,60,73]$. Both arguments support an overproportional increase of information processing complexity. This course is modeled by joining the complexity factors multiplicatively. As each coefficient's value is restricted to the interval [0;1], this holds true for their product, which equals 0 if $M_{\text {cons }}$ encloses no measures and 1 if $M_{\text {cons }}$ encloses all existing measures. Analogous to the positive informational effects, the overall fraction needs to be monetized. This is done by multiplying it with the decision makers' subjective monetary equivalent $S$ of coping with the information complexity induced by $M$. One possibility of determining the value of $S$ relies on the concept of opportunity costs. In this sense, the amount of time the involved decision makers have to spend understanding and discussing the information provided by the existing PMS can serve as a proxy attribute [72]. Based on an average daily rate and a daily working time, one could calculate the opportunity costs as an average subjective monetary equivalent [70].

\subsubsection{Negative Economic Effects}


In the preceding subsections, the informational perspective of PMS consolidation has been addressed. What remains is the economic perspective captured by means of objective (O.4), i.e., the costs of information provision resulting from operating and maintaining the supporting infrastructure. We distinguish three cost categories with different cost drivers and reference objects.

The first cost category refers to platform costs that are necessary for operating the underlying information systems (e.g., hardware, technical administration, or software licenses). Though it makes up the largest part of total costs in most cases, this cost category can be considered fixed and thus be neglected in the context of PMS consolidation because platform costs arise for any consolidated PMS and do not depend on their size or composition. Moreover, it is highly improbable that hardware and software will be deactivated in business practice based on the results of PMS consolidation. In line with the reporting costs mentioned by Jensen and Sage [40] and the costs for customizing and maintaining reporting tools proposed by Röglinger [70], the second cost category addresses costs for configuring, preparing, maintaining, and disseminating management reports. These costs depend on the number of measures enclosed in the consolidated PMS. In this context, labor costs typically outvalue by far any other reporting costs as the preparation of management reports in general and especially the preparation of special requests is a time-consuming and manual activity. If the consolidated PMS encloses a reduced number of measures, configuration and preparation (e.g., layout, representation, interpretation, and annotations) will require less effort and lower costs. The third cost category covers costs for data collection and quality assurance in the context of ETL procedures. These costs depend on the composition of the consolidated PMS. For example, the raw data for some measures may be retrieved automatically from an enterprise resource planning system, whereas the raw data for other measures may have to be collected manually. The same holds true for the quality of input data (e.g., timeliness, correctness, completeness). If a measure is dropped from the existing PMS of the business unit under consideration, the respective costs cannot be assigned to the consolidated PMS anymore. The negative economic effects of the consolidated PMS decrease accordingly. Nonetheless, the costs may incur for the company at large if the measure is used by other business units. 
Based on these considerations, we propose to formalize the negative economic effects (NEE) of a particular consolidated PMS $M_{\text {cons }}$ as follows:

$$
\operatorname{NEE}\left(M_{\text {cons }}\right)=\frac{\left|M_{\text {cons }}\right|}{|M|} \cdot C_{M}+\sum_{m_{i} \in M_{\text {cons }}} c_{i}
$$

where $C_{M} \in \mathbb{R}^{+}$

$$
\begin{aligned}
& c_{i} \in\left\{d_{1}, d_{2}, \ldots, d_{l}\right\} \quad \text { is the individual cost level assigned to } m_{i} \text {, and } \\
& 0<d_{1}<d_{2}<\cdots<d_{l}, d_{i} \in \mathbb{R}^{+} \text {are cost levels. }
\end{aligned}
$$

Equation (3) can be interpreted as follows: The first addend represents the costs that depend on the number of measures enclosed in $M_{\text {cons }}$. Therefore, the fraction of the existing measures that is enclosed in $M_{\text {cons }}$ is multiplied by $C_{M} \in \mathbb{R}^{+}$. The second addend represents the costs that depend on the composition of $M_{\text {cons }}$. For its calculation, we proceed analogous to the determination of the measure-specific information processing complexity, as it seems reasonable to determine a measure's individual costs approximately and in relation to other measures. We therefore define several cost levels $d_{i}$, measured in a fixed currency, assign a specific cost level $c_{i} \in\left\{d_{1}, d_{2}, \ldots, d_{l}\right\}$ to each measure $m_{i} \in M_{\text {cons }}$, and build the sum of the measure-specific cost levels.

\subsection{Objective Function}

Finally, the mathematical functions that operationalize the objective system of the decision framework have to be integrated into an overall objective function. This function has to reflect the complementary and conflicting relationships among the objectives. A commonly used option is to integrate the mathematical functions into an additive objective function. In the problem setting at hand, the negative informational and economic effects of a consolidated PMS $M_{\text {cons }}$ have to be subtracted from the re- 
spective positive informational effects. In line with MCDA, using an additive objective function is allowed if the following assumption holds $[23,43]$ :

(A.4) Objectives (O.1) to (O.4) are mutually preferential independent. Changes in the realizations of one objective can be compensated by the realizations of other objectives.

Against this backdrop, we propose the following objective function:

$$
\begin{aligned}
\max _{M_{\text {cons }} \in M} P I E\left(M_{\text {cons }}\right) & -N I E\left(M_{\text {cons }}\right)-N E E\left(M_{\text {cons }}\right) \\
= & {\left[\lambda \cdot \frac{\left.\left|M_{\text {cons }}\right|+\sum_{m_{i} \in M \backslash M_{\text {cons }} R^{2}\left(M_{\text {cons }}, m_{i}\right)}^{|M|}+(1-\lambda) \cdot R^{2}\left(M_{\text {cons }}, m_{\text {top }}\right)\right] \cdot I}{}\right.} \\
& -\left[\frac{\left|M_{\text {cons }}\right|}{|M|} \cdot \frac{\sum_{m_{i} \in M_{\text {cons }}} e_{i}}{\sum_{m_{i} \in M} e_{i}} \cdot \frac{u_{M_{\text {cons }}}}{u_{M}}\right] \cdot S-\left[\frac{\left|M_{\text {cons }}\right|}{|M|} \cdot C_{M}+\sum_{m_{i} \in M_{\text {cons }}} c_{i}\right]
\end{aligned}
$$

We deliberately refrain from using further weighting factors because the importance of each objective is expressed by means of the decision makers' subjective monetary equivalents (i.e., $I$ and $S$ ) and the costs for operations and maintenance of the supporting infrastructure. As PMS consolidation is a discrete problem with a finite set of alternatives, the objective function provides a means for valuating and comparing different consolidated PMS. The consolidated PMS for which the objective function reaches the highest value should be selected according to the decision framework. We will discuss in the next section that, due to the inevitable inaccuracies of parameter estimation, the results of the decision framework should be interpreted as recommendations. When applying the decision framework in real-world settings, further sensitivity and scenario analyses should be conducted before starting organizational change projects. 


\section{Evaluation of the Decision Framework}

\subsection{Overview}

As the evaluation of artifacts is an important phase of design-oriented research, a variety of methods and patterns to perform the evaluation are available $[36,68,81]$. To evaluate the decision framework for PMS consolidation, we use feature comparison, prototype construction, and a real-world application. Feature comparison is a method of discursive evaluation in which the characteristics of the artifact are compared with a checklist of requirements that should be met by a useful solution to the problem [26,74]. Two recent applications that serve as examples are reported in El-Gayar and Fritz as well as Strecker et al. [19,78]. Prototype construction provides a proof of concept that the features of the proposed artifact can be realized by means of information technology. Feature comparison and prototype construction are suitable for assessing whether an artifact contributes to closing the research gap. It is reasonable to apply these evaluation methods here because the decision framework has not yet been adopted by the industry [36,78]. The real-world application complements the other two evaluation steps as it allows for an empirical assessment of whether the decision framework proves useful for subject matter experts who are involved in PMS consolidation.

\subsection{Feature Comparison}

Regarding feature comparison, the characteristics of the decision framework are compared with the requirements introduced in section 2.2. This is reasonable because, according to the literature, these requirements characterize a useful PMS, and they have been used to identify the research gap. The characteristics of the decision framework are summarized and discussed in Table 3. The discussion also reveals limitations and opportunities for future research, to which we return in section 6. Overall, the decision framework addresses all requirements - particularly those identified as particularly requiring additional research, i.e., (R.3) to (R.5) - in an integrated and quantitative manner. All requirements with a focus on PMS as design products have been integrated into the objective function of the decision framework. The objective function thus covers the informational and economic 
perspectives of PMS consolidation. The requirements that refer to the process of PMS design are considered in the mathematical operationalization and the quantitative nature of the decision framework.

$$
<<\text { Insert Table } 3 \text { about here }>>
$$

\subsection{Prototype Construction}

In order to provide a proof of concept, the decision framework was implemented using Microsoft Excel and IBM SPSS Statistics 19. The Excel component of the prototype helps organize the input parameters and intermediate results for all components of the decision framework's objective function. It also displays the final results and allows for basic sensitivity and scenario analyses. The functionality of SPSS enables conducting regression analyses and tests of significance.

The input parameters stored in the Excel component include the historical values of the top measure and all measures from the existing PMS as well as measure-specific meta-data such as the measures' names, units, complexity levels, and costs. Further parameters such as the decision makers' subjective monetary equivalents, overarching costs, and the business unit-specific weighting factor belong to the input parameters as well. The intermediate results comprise all bivariate correlation coefficients, the coefficients of determination from the regression analyses, and the test statistics for each regression analysis. They also include the values for each component of the decision framework's objective function and each different consolidated PMS. The final results show which value the objective function takes for each consolidated PMS, which PMS maximizes the objective function, and what measures this PMS encloses.

The following steps have to be followed when applying the prototype: First, the input parameters have to be fed into the Excel component. The intermediate results for the negative informational effects and the negative economic effects are available immediately after the input parameters have been provided because their calculation does not depend on the results of any statistical analyses. Second, an SPSS routine, which is based on the SPSS application programming interface, needs to be invoked to 
prepare the calculation of the positive informational effects. This routine determines all possible subsets of the existing PMS, conducts regression analyses for different subsets, calculates coefficients of determination as well as test statistics and stores the output as intermediate results in the Excel component. The Excel component then determines the positive informational effects of all different consolidated PMS. Third, the final results are presented to the user. The user may now conduct basic sensitivity and scenario analyses.

In its current form, the prototype does not provide further assistance in estimating the input parameters' values. It is able to deal with existing PMS of up to ten measures, which we considered sufficient for a proof of concept. Conducting the required regression analyses for a PMS of ten measures takes about 20 minutes, using a regular workstation. In our opinion, this considerable calculation effort is tolerable because PMS consolidation is unlikely to be repeated in very short intervals. Despite the size limitation, the prototype was implemented in such a way that it could easily be adapted to deal with a higher number of measures. For us, the most important insight from prototype construction was that all features of the decision framework for PMS consolidation could be realized by means of information technology.

\subsection{Real-world Application}

Besides feature comparison and prototype construction, the decision framework and the prototype were applied at the strategic production planning department of an international company in the semiconductor industry. The department is responsible for the supply chain reporting and the PMS of the company's operations department. Two members of the department's management team helped us reflect on the decision framework and collect data for the input parameters. Owing to confidentiality, the identity of the company will not be disclosed. All data had to be anonymized and slightly modified. However, the principal results still hold. We were not able to cope with the complexity of the entire existing PMS because of the restrictions of the prototype outlined in section 5.3. Nevertheless, we gained valuable insights into the difficulties encountered during data collection and 
analysis, whether the decision framework creates utility, and which topics might be of interest for future research from the subject matter experts' viewpoint.

As for data collection, we had access to the historical data of ten operations and supply chain performance measures, which represent a subset of the overall PMS used for managing the company's operations department, as well as to the data of a top measure. While the overall PMS covers the production process including the back-end and the front-end stage, our subset focuses on one of these stages. Five measures address the supply chain (SC) performance, two measures the loading and cost performance (LC), and another three measures the yield and quality performance (YQ). Accordingly, we denote the PMS under investigation and the measures it encloses as $M=\left\{S C_{1}, \ldots, S C_{5}, L C_{1}, L C_{2}\right.$, $\left.Y Q_{1}, Y Q_{2}, Y Q_{3}\right\}$. The top measure is a customized form of earnings before interest and taxes. It is reported for each business unit and on a corporate level. As not all measures could be unambiguously assigned to a single business unit, we used the values reported at the corporate level.

When treating the historical data, we faced a couple of challenges: First, owing to numerous carve outs and acquisitions in the company's recent past, the subject matter experts were able to provide only a data set that covers 21 comparable months. From a theoretical point of view, a longer period would have been desirable because the PMS encloses ten measures, which results in up to ten independent variables as input for multiple linear regression. Since we obtained statistically significant results, we proceeded with the restricted data set. Second, while the measures enclosed in the PMS were reported monthly, the top measure was available on a quarterly basis only. Hence, we had to approximate the missing values for the second and third month of each quarter to make all measures comparable. We assumed a linear development from quarter to quarter. Third, the time series of some measures had very few missing values. Analogous to how we treated the top measure, the missing values were estimated by means of a linear approximation on the basis of the values of the preceding and succeeding months respectively. Fourth, we tried to figure out whether there is a lag between the points in time when the values of the measures from the PMS are obtained and when they take effect on the top measure. The experts stated that there certainly is a time lag, which can be predicted fairly 
well for some measures, but not at all for others. Regarding the case at hand, they argued that the effects cancel out each other. We therefore refrained from more detailed analyses.

Further, we assessed the other input parameters of the decision framework's objective function. We developed a catalogue of questions, which the subject matter experts were asked during a two-hour interview. All input parameters that could not be assessed in the interview, such as labor costs of IT experts or engineers, were estimated by conducting benchmark analyses and Internet research. For the components of the objective function to be comparable, all monetary parameters were calculated on a yearly basis.

Regarding the positive informational effects, the decision makers' subjective monetary equivalent of having all information provided by the existing PMS as well as perfect alignment with the company's objectives at a corporate level was interpreted as the perceived value of the existing PMS. The perceived value was measured by the estimated effort to reconstruct it in a new project, including the necessary systems and procedures for the data collection, data assimilation, and presentation as well as the integration of external data. Such a project was said to take about two years and to require a team of about 25 IT experts and 25 business experts located at the company's headquarters and business units. The total project cost, including the average labor costs for IT and business experts, amounts to 2,400,000 EUR. This corresponds to a subjective monetary equivalent of 1,200,000 EUR per year. As production processes in the semiconductor industry are highly complex and the operations department is critical for the company's overall success, it is important to cover the information provided by the existing PMS. Therefore, the business unit-specific weighting factor was set to 0.8 .

The negative informational effects require determining the decision makers' subjective monetary equivalent of coping with the information processing complexity caused by the existing PMS. Relying on the concept of opportunity costs, we examined how often the corresponding management report is discussed, who participates in the management meetings, and how much time these persons spend on preparing for and attending the meetings. The report is prepared once a month and then disseminated to about 40 recipients. It is analyzed by a team of about 25 managers ranging from department heads 
to the Chief Operating Officer. The report is discussed thoroughly during a six-hour meeting. With average labor costs for different management levels, the subjective monetary equivalent amounts to 200,000 EUR per year. The measures' individual complexity and their units are shown in Table 4.

Regarding the negative economic effects, we assessed the costs for configuring, preparing, maintaining, and disseminating the management reports using all measures of the PMS under consideration. The economic components in particular were difficult to operationalize. We adopted with the following solution: We estimated how much time is necessary to conduct the tasks listed above and to process ad-hoc requests. Since many of these tasks require experienced professionals, we considered average labor costs for senior engineers. This resulted in yearly costs of 100,000 EUR. Additionally, the experts were asked to indicate the effort associated with data collection and quality assurance for each measure. This was translated into the individual cost levels shown in Table 4. The cost levels are rather high because many of the measures have to be treated manually.

\section{$<<$ Insert Table 4 about here $>>$}

After data collection, we calculated the value of the objective function for each subset of the existing PMS through the prototype. The consolidated PMS $M_{\text {cons }}^{*}$ for which the objective function reaches the highest value contains six measures: $S C_{2}, S C_{3}, S C_{5}, L C_{1}, Y Q_{1}$, and $Y Q_{3}$. This corresponds to a reduction of $40 \%$ in the number of measures. Moreover, the information complexity and the costs for operating and maintaining the supporting infrastructure could be reduced by $75 \%$ and $40 \%$ respectively. The enclosed measures on average explain $97 \%$ of the variance of each measure from the existing PMS and $90 \%$ of the top measure's variance. Moreover, the optimal consolidated PMS still covers all performance dimensions relevant to the subject matter experts.

For a deeper understanding of the final results, we analyzed the intermediate results provided by the prototype. It can be seen that the values of the objective function for the different consolidated PMS are very close, which might at first sight be seen as indicative of non-robust results. A closer look, however, reveals the optimal consolidated PMS is robust with respect to size and content. The top 25 consolidated PMS in terms of the objective function, encompass either five (eight times) or six 
measures (17 times). The best consolidated PMS enclosing seven measures is ranked $26^{\text {th }}$, and the best consolidated PMS with four measures is ranked $91^{\text {st }}$. The value of the objective function achieved by the best consolidated PMS with seven and four measures differs by $4 \%$ and $7 \%$, respectively, from the value achieved by the optimal consolidated PMS. This is considerable if one takes into account that, on average, two consecutive consolidated PMS from the top 25 differ by about $0.1 \%$ only. In addition, three measures from the optimal consolidated PMS (i.e., $S C_{3}, S C_{5}, Y Q_{3}$ ) are enclosed in more than 20 of the top 25 consolidated PMS, while the other three measures (i.e., $S C_{2}, L C_{1}, Y Q_{1}$ ) are part of more than 10 of the top 25 consolidated PMS. This is corroborated by an analysis of the bivariate correlation coefficients. The measures $S C_{3}$ and $S C_{5}$, for example, interdepend strongly with different nonenclosed measures and thus create highly positive informational effects. The measure $Y Q_{3}$, in contrast, interdepends with almost no other measure, so its absence cannot be compensated for by any enclosed measure. In addition, the measures $S C_{3}, S C_{5}$, and $Y Q_{3}$ do not interdepend with one another.

Overall, the decision framework created utility for the subject matter experts as it provided them with recommendations and means for further analysis. It also helped systematize the consolidation processes. Thus, the subject matter experts could triangulate their gut feeling about important measures as well as the understanding they believed to be correct about the relationships governing the business unit with the proposals made by the decision framework.

Besides the application of the decision framework, the discussions with the subject matter experts revealed further topics related to PMS consolidation that, from their viewpoint, might be of interest for future research. Besides the challenge of ensuring high data quality in a complex and globally distributed organization, one of the experts' main challenges arise in adapting their performance measurement activities to changing information requirements of the management. In economic downturns, for example, the company's supply chain reporting focuses much more on cashflowrelated measures, whereas strong emphasis is laid on quality- and efficiency-related measures in economic upturns. Consequently, in research on PMS consolidation, it may be necessary to take some measures out of the PMS temporarily when they are not the focus of reporting. During this period, 
these measures entail neither positive nor negative informational effects; rather, they entail negative economic effects as data collection and quality assurance have to be continual in order for the measures to be reintegrated into the reporting quickly and with up-to-date values. Moreover, research is needed to determine which PMS should be consolidated with respect to which top measure, how potential hierarchic relationships between PMS can be addressed, and how interdependencies among top measures and the measures enclosed in different PMS should be treated. The last topic mentioned relates to the fact that currently only the final results of applying the decision framework are used to adapt the content of reports. Performance measurement research should investigate how input parameters (e.g., measure-specific levels of information processing complexity; costs for data collection and for quality assurance) as well as intermediate results (e.g., the strengths of the interdependencies among the existing measures; the results from multiple regression analysis) can be leveraged to improve the decision makers' overall understanding of the unit of analysis and a company's performance measurement activities in entirety.

In summary, the results of all the applied evaluation methods confirm that the decision framework makes an incremental contribution to meeting the requirements for useful solutions to the problem of PMS consolidation. Moreover, the decision framework can be implemented by means of information technology and appears to be useful in assisting subject matter experts from the industry in carrying out the consolidation of existing PMS.

\section{Conclusion and Outlook}

In this paper, we addressed the question of how existing PMS can be consolidated in line with the informational and economic challenges of information provision. PMS are interpreted as conceptual artifacts that enclose multiple interdependent measures and rely on a supporting infrastructure comprising information systems and procedures of information provision. To answer the research question, we followed a design science research approach and drew from the MCDA knowledge base. Our arti- 
fact is a decision framework for PMS consolidation. The construction of this framework was guided by PMS-related requirements extracted from the management accounting, operations management, and performance measurement literature. The requirements address the informational and economic perspectives of PMS consolidation, considering PMS as design products and the process of PMS design. In line with these requirements, the objective function of the decision framework includes components that refer to the coverage of the decision makers' information requirements, the alignment with corporate objectives, adequate information processing complexity, and adequate costs for operations and maintenance of the supporting infrastructure. Each component is operationalized by means of a mathematical function such that both the measures of existing PMS and the interdependencies among these measures are considered. Moreover, decision makers and subject matter experts are involved systematically.

The decision framework provides assistance in consolidating existing PMS against the background of partially conflicting informational and economic objectives. Thereby, the information processing complexity and the costs for operating and maintaining the supporting infrastructure can be reduced in a manner that is reasonably balanced with the extent to which a consolidated PMS covers the information requirements and aligns with the company's objectives at a corporate level. Due to the fact that many parts of the PMS consolidation process can be automated - as demonstrated by the prototypemanual effort can be reduced as well. Contrasted with existing approaches and based on the evaluation results, the decision framework is an integrated and quantitative approach that makes an incremental contribution to solving the problem of PMS consolidation.

Both the decision framework and its applicability are beset with limitations that motivate future research in the field of PMS consolidation. Some limitations have already been discussed in section 5 .

1. Some assumptions of the decision framework are simplifying. For example, we assume that the company's objectives are captured by means of a single top measure, that the interdependencies among measures are linear and constant, or that the heterogeneity of the measures enclosed in a PMS can be quantified by means of the number of different units. It has to be challenged in future 
research which of these assumptions can and should be relaxed. One has to keep in mind that the decision framework is a model of the real world conceived by purposeful abstraction that does not intend to capture all the complexity of the real world. Thus, it is imperative to deliberate carefully whether the increase in closeness to reality gained by relaxing certain assumptions outvalues the increase in the decision framework's complexity and the additional effort of eliciting values for the input parameters.

2. So far, the scope of the decision framework is limited to a single business unit. Multiple business units can only be addressed successively and in isolation. Moreover, the case that measures are thematically appropriate for multiple business units is neglected. Taking on a single business unit perspective also constrains the alignment with corporate objectives because we can only use the "fractional" contribution of the business unit under investigation. The fractional contribution of other business units and potential diversification effects are ignored. An integrated investigation of multiple business units would be desirable and of importance for practice and research.

3. As for almost all formal models, the main difficulty of applying the decision framework in practice is determining valid values for the input parameters. The mathematical operationalization proposed for the components of the decision framework's objective function intend to mitigate this difficulty, for example, by relying on cost and complexity levels instead of detailed assessments. We provide additional guidance, for example on how to determine values for decision makers' subjective monetary equivalents, as well as lessons learned from applying the decision framework in a real-world setting. Nevertheless, the practical applicability would benefit from identifying and assessing other ways for operationalizing the decision framework's input parameters. One should involve multiple case studies and extensive discussions with subject matter experts from industry.

4. The decision framework was evaluated by means of feature comparison, prototype construction, and a real-world application. In line with the recommendations for an enhanced practical applicability, further evaluation steps should be conducted to assess how the artifact can be applied in real-world settings, creates utility, and outperforms competing artifacts. This, however, needs to be 
done in future research endeavors because the context and data currently available from reports on the application of existing approaches to PMS consolidation are not rich enough to enable a comparison with the decision framework. In the course of further evaluation, the prototype that is currently based on Microsoft Excel and IBM SPSS Statistics 19 should be improved as well, for example, with respect to interfaces to data sources, a more convenient user interface, and support for eliciting values for the decision framework's input parameters.

Despite these potentials for improvement, the decision framework enriches the body of knowledge related. We hope that it helps fellow researchers with their work on PMS consolidation.

\section{References}

[1] R. Ackoff, Management Misinformation Systems, Management Science 14 (1967) B147-B156.

[2] D. Arnott, W. Jirachiefpattana, P. O'Donnell, Executive information systems development in an emerging economy, Decision Support Systems 4 (2007) 2078-2084.

[3] D. Arnott, G. Dodson, Decision Support Systems Failure, in: F. Burstein, C.W. Holsapple (Eds.), Handbook on Decision Support Systems 1, Springer, Berlin, 2008, pp.763-790.

[4] W. Artley, S. Stroh, The Performance-based Management Handbook (Volume Two), 2001.

[5] D. Axson, Best Practices in Planning and Performance Management, 3 ed., John Wiley \& Sons, Hoboken, 2010.

[6] D. Bawden, L. Robinson, The dark side of information: overload, anxiety and other paradoxes and pathologies, Journal of Information Science 2 (2009) 180-191.

[7] V. Belton, T.J. Stewart, Multiple criteria decision analysis: an integrated approach, 2 ed., Springer, New York, 2003.

[8] U.S. Bititci, A.S. Carrie, L. McDevitt, Integrated performance measurement systems: a development guide, International Journal of Operations \& Production Management 5/6 (1997) 522-534.

[9] M. Bourne, M. Kennerley, M. Franco-Santos, Managing through measures: a study of impact on performance, Journal of Manufacturing Technology Management 4 (2005) 373-395.

[10] M. Bourne, J. Mills, M. Wilcox, A. Neely, K. Platts, Designing, implementing and updating performance measurement systems, International Journal of Operations \& Production Management 7 (2000) 754-771.

[11] R.A. Brealey, S.C. Myers, Principles of Corporate Finance, 9 ed., McGraw-Hill, Inc., New York, 2008.

[12] H.U. Buhl, M. Röglinger, S. Stöckl, K. Braunwarth, Value Orientation in Process Management Research Gap and Contribution to Economically Well-founded Decisions in Process Management, Business \& Information Systems Engineering 3 (2011) 163-172.

[13] F. Burstein, C.W. Holsapple, Handbook on Decision Support Systems 1: Basic Themes , 1 ed., Springer, Berlin, 2008. 
[14] C. Caplice, Y. Sheffi, A Review and Evaluation of Logistics Performance Measurement Systems, The International Journal of Logistics Management 1 (1995) 61-74.

[15] J.L. Cohon, Multiobjective programming and planning, 2 ed., Dover Publishings, New York, 2004.

[16] G.G. Dess, R.B. Robinson Jr, Measuring organizational performance in the absence of objective measures: the case of the privately-held firm and conglomerate business unit, Strategic Management Journal 3 (1984) 265-273.

[17] J. Duncan, The Demonstration of Capacity Limitation, Cognitive Psychology 1 (1980) 75-96.

[18] R. Eccles, The Performance Measurement Manifesto, Harvard Business Review 1 (1991) 131137.

[19] O. El-Gayar, B. Fritz, A web-based multi-perspective decision support system for information security planning, Decision Support Systems 1 (2010) 43-54.

[20] M.J. Eppler, J. Mengis, The concept of information overload: A Review of Literature from Organization Science, Marketing, Accounting, MIS, and related Disciplines, The Information Society: An International Journal 20 (2004) 1-20.

[21] A.F. Farhoomand, D.H. Drury, Managerial Information Overload, Communications of the ACM 10 (2002) 127-131.

[22] J. Figueira, S. Greco, M. Ehrgott, Multiple criteria decision analysis: state of the art surveys, 1 ed., Springer, New York, 2005.

[23] P.C. Fishburn, Utility Theory for Decision Making, 1 ed., Krieger Publishing Co., New York, 1970.

[24] M. Franco-Santos, M. Bourne, An examination of the literature relating to issues affecting how companies manage through measures, Production Planning \& Control 2 (2005) 114-124.

[25] M. Franco-Santos, M. Kennerly, P. Micheli, V. Martinez, S. Mason, B. Marr, D. Gray, A. Neely, Towards a Definition of a Business Performance Measurement System, International Journal of Operations \& Production Management 8 (2007) 784-801.

[26] U. Frank, Towards a pluralistic conception of research methods in information systems research, ICB, Essen, 2006.

[27] M.N. Frolick, T.R. Ariyachandra, Business performance management: One truth, Information Systems Management 1 (2006) 41-48.

[28] J. Gantz, A. Boyd, S. Dowling, Cutting the Clutter: Tackling Information Overload at the Source, 2009, 08-07, http://www.xerox.com/assets/motion/corporate/pages/programs/informationoverload/pdf/Xerox-white-paper-3-25.pdf,

[29] M. Gibson, D. Arnott, Evaluating the intangible benefits of business intelligence: review \& research agenda, Proceedings of the 2004 IFIP International Conference on Decision Support Systems (DSS2004): Decision Support in an Uncertain and Complex World, Caulfield East, Autralia, 2004, pp. 295-305.

[30] W. Gladen, Performance Management. Controlling mit Kennzahlen, 4 ed., Gabler, Wiesbaden, 2008.

[31] S. Globerson, Issues in developing a performance criteria systems for an organization, International Journal of Production Research 4 (1985) 639-646.

[32] W. Greene, Econometric Analysis, 5 ed., Prentice Hall, Upper Saddle River, 2003. 
[33] S. Gregor, D. Jones, The Anatomy of a Design Theory, Journal of the Association for Information Systems 5 (2007) 312-335.

[34] Hackett Group Benchmarking, Corporate Strategic Planning Suffers From Inefficiencies, (1999)

[35] J.F. Hair, W.C. Black, B.J. Babin, R.E. Anderson, Multivariate Data Analysis, 6 ed., Pearson Prentice Hall, New Jersey, 2006.

[36] A.R. Hevner, S.T. March, J. Park, S. Ram, Design Science in Information Systems Research, MIS Quarterly 1 (2004) 75-105.

[37] W. Inmon, Building the Data Warehouse, 5 ed., Wiley-India, Indianapolis, 2009.

[38] E.R. Iselin, L. Mia, J. Sands, Multi-perspective performance reporting and organisational performance: the impact of information, data and redundant cue load, International Journal of Accounting, Auditing and Performance Evaluation 1 (2010) 1-27.

[39] C.D. Ittner, D.F. Larcker, T. Randall, Performance implications of strategic performance measurement in financial services firms, Accounting, Organizations and Society 7-8 (2003) 715-741.

[40] A.J. Jensen, A.P. Sage, A systems management approach for improvement of organizational performance measurement systems, Information, Knowledge, Systems Management 1 (2000) 33-61.

[41] R. Johnston, S. Brignall, L. Fitzgerald, 'Good enough' performance measurement: a trade-off between activity and action, Journal of the Operational Research Society 3 (2002) 256-262.

[42] R.S. Kaplan, D.P. Norton, The Balanced Scorecard: Translating Strategy Into Action, Harvard Business School Press, Boston, 1996.

[43] R.L. Keeney, H. Raiffa, Decisions with multiple objectives: Preferences and value tradeoffs, Cambridge University Press, Cambridge, 1993.

[44] M. Kennerley, A. Neely, A framework of the factors affecting the evolution of performance measurement systems, International Journal of Operations \& Production Management 11 (2002) 12221245.

[45] I.C. Kerssens-Van Drongelen, O. Fisscher, Ethical dilemmas in performance measurement, Journal of Business Ethics 1/2 (2004) 51-63.

[46] D.G. Kleinbaum, L.L. Kupper, K.E. Muller, Applied Regression Analysis and Other Multivariable Methods, 4 ed., Duxbury, Belmont, CA, 2008.

[47] H. Küpper, Controlling: Konzeption, Aufgaben, Instrumente, 5 ed., Schäffer-Poeschel, Stuttgart, 2008.

[48] M. Lebas, K. Euske, A conceptual and operational delineation of performance, in: A. Neely (Eds.), Business performance measurement: unifying theories and integration practice, Cambridge University Press, Cambridge, 2007, pp.125-139.

[49] D. Lewis, Dying for information? An investigation into the effects of information overload in the UK and worldwide, London: Benchmark Research, Reuters Business Information (1996)

[50] R. Libby, Accounting and human information processing: Theory and applications, 1 ed., Prentice-Hall, Englewood Cliffs, 1981.

[51] M.G. Lipe, S. Salterio, A note on the judgmental effects of the balanced scorecard's information organization, Accounting, Organizations and Society 6 (2002) 531-540.

[52] G. Maddala, K. Lahiri, Introduction to Econometrics, 4 ed., John Wiley \& Sons, West Sussex, 2009.

[53] M. Malina, H. Norreklit, F. Selto, Relations among measures, climate of control, and performance measurement models, Contemporary Accounting Research 3 (2007) 935-982. 
[54] N. Manoochehr, J. Rigas, I. Fan, A framework to review performance measurement systems, Business Process Management Journal 2 (2005) 109-122.

[55] S.T. March, G.F. Smith, Design and natural science research on information technology, Decision Support Systems 4 (1995) 251-266.

[56] M. Marchand, L. Raymond, Researching performance measurement systems - An information systems perspective, International Journal of Operations \& Production Management 7 (2008) 663-686.

[57] H.M. Markowitz, Portfolio Selection, Journal of Finance 1 (1952) 77-91.

[58] B. Maskell, Performance Measurement for World Class Manufacturing: A Model for American Companies, Productivity Press, Cambridge, 1991.

[59] D. Medori, D. Steeple, A framework for auditing and enhancing performance measurement systems, International Journal of Operations \& Production Management 5 (2000) 520-533.

[60] G. Miller, The Magical Number Seven, Plus or Minus Two: Some Limits on Our Capacity for Processing Information, The Psychological Review 2 (1956) 81-97.

[61] M.D. Myers, M. Newman, The qualitative interview in IS research: Examining the Craft, Information and Organization 1 (2007) 2-26.

[62] A. Neely, J. Mills, K. Platts, H. Richards, M. Gregory, M. Bourne, M. Kennerley, Performance measurement system design: developing and testing a process-based approach, International Journal of Operations \& Production Management 9/10 (2000) 1119-1145.

[63] A. Neely, The evolution of performance measurement research - Developments in the last decade and a research agenda for the next, International Journal of Operations \& Production Management 12 (2005) 1264-1277.

[64] A. Neely, M. Gregory, K. Platts, Performance measurement systems design: A literature review and research agenda, International Journal of Operations \& Production Management 4 (1995) 80-116.

[65] H. Norreklit, The balance on the balanced scorecard: a critical analysis of some of its assumptions, Management Accounting Research (2000) 65-88.

[66] S.S. Nudurupati, U.S. Bititci, V. Kumar, F.T.S. Chan, State of the art literature review on performance measurement, Comput.Ind.Eng. 2 (2011) 290.

[67] D. Otley, Performance management: a framework for management control systems research, Management accounting research 4 (1999) 363-382.

[68] K. Peffers, T. Tuunanen, M.A. Rothenberger, S. Chatterjee, A Design Science Research Methodology for Information Systems Research, Journal of Management Information Systems 3 (2008) 4577.

[69] T. Reichmann, Controlling mit Kennzahlen: Die systemgestützte Controlling-Konzeption mit Analyse- und Reportinginstrumenten, 8 ed., Vahlen, München, 2011.

[70] M. Röglinger, How to select measures for decision support systems - An optimization approach integrating informational and economic objectives, Proceedings of the 17th European Conference on Information Systems, ECIS, Verona, Juni 2009, pp. 2856-2868.

[71] B. Roy, Paradigms and challenges, in: J. Figueira, S. Greco (Eds.), Multiple criteria decision analysis: state of the art surveys, Springer, New York, 2005, pp.3-24.

[72] W.F. Samuelson, S.G. Marks, Managerial Economics, 6 ed., John Wiley \& Sons, Hoboken, NJ, 2010.

[73] H.M. Schroder, M.J. Driver, S. Streufert, Human information processing - individuals and groups functioning in complex social situations, 1 ed., Holt, Rinehart and Winston, New York, 1967. 
[74] K. Siau, M. Rossi, Evaluation of Information Modeling Methods - A Review Proceedings of the 31st Hawaii International Conference on Systems Sciences, Los Alamitos, pp. 314-324.

[75] H. Simon, The Sciences of the Artificial, 3 ed., MIT Press, Cambridge, 1996.

[76] G.W. Sousa, L.C. Carpinetti, R.L. Groesbeck, E. Van Aken, Conceptual design of performance measurement and management systems using a structured engineering approach, International Journal of Productivity and Performance Management 5/6 (2005) 385-399.

[77] K. Steininger, R. Riedl, F. Roithmayr, P. Mertens, Fads and Trends in Business and Information Systems Engineering and Information Systems Research-A Comparative Literature Analysis, Business \& Information Systems Engineering 6 (2009) 411-428.

[78] S. Strecker, U. Frank, D. Heise, H. Kattenstroth, MetricM: A modelling method in support of the reflective design and use of performance measurement systems, Inf Syst E-Bus Manage (2011) 1-36.

[79] J. Sweller, Evolution of human cognitive architecture, The Psychology of Learning and Motivation (2003) 215-266.

[80] M.L. Tushman, D.A. Nadler, Information processing as an integrating concept in organizational design, Academy of Management Review 3 (1978) 613-624.

[81] V. Vaishnavi, W. Kuechler, Design Science Research Methods and Patterns: Innovating Information and Communication Technology, Auerbach Publications, Boca Raton, 2008.

[82] J. Webster, R.T. Watson, Analyzing the Past to Prepare for the Future: Writing a Literature Review, MIS Quarterly 2 (2002) xiii-xxiii.

[83] M. Wouters, M. Sportel, The role of existing measures in developing and implementing performance measurement systems, International Journal of Operations \& Production Management 11 (2005) 1062-1082. 


\begin{tabular}{|c|c|c|c|c|c|}
\hline & & Identifier & Description & Perspective & $\begin{array}{l}\text { Exemplary } \\
\text { justificatory } \\
\text { references }\end{array}$ \\
\hline \multirow{4}{*}{ 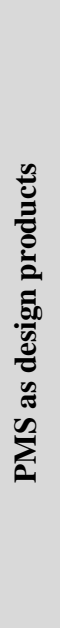 } & (R.1) & $\begin{array}{l}\text { Coverage of the deci- } \\
\text { sion makers' infor- } \\
\text { mation requirements }\end{array}$ & $\begin{array}{l}\text { The measures enclosed in a PMS should enable the involved decision makers to manage the fields of action } \\
\text { within their responsibility. Therefore, the measures should cover the decision makers' related information } \\
\text { requirements, reflect the decision makers' objectives, and refer to the phenomena of interest. The PMS at } \\
\text { large should constitute a balanced portfolio of different types of measures. }\end{array}$ & Informational & {$[4,14,24,30,42,58,83]$} \\
\hline & (R.2) & $\begin{array}{l}\text { Alignment with corpo- } \\
\text { rate objectives }\end{array}$ & $\begin{array}{l}\text { The measures enclosed in a PMS should enable the involved decision makers to manage the fields of action } \\
\text { within their responsibility in line with the company's strategy and objectives at a corporate level. }\end{array}$ & Informational & {$[4,14,24,31,42,58,83]$} \\
\hline & (R.3) & $\begin{array}{l}\text { Adequate information } \\
\text { processing complexity }\end{array}$ & $\begin{array}{l}\text { The complexity incurred for cognitively processing the information conveyed by the measures enclosed in a } \\
\text { PMS should be adequate with respect to the provided information. }\end{array}$ & Informational & {$[4,6,14,20,47,69]$} \\
\hline & (R.4) & $\begin{array}{l}\text { Adequate costs for } \\
\text { operations and mainte- } \\
\text { nance of the supporting } \\
\text { infrastructure }\end{array}$ & $\begin{array}{l}\text { The costs incurred for operating and maintaining the supporting infrastructure necessary to report and ana- } \\
\text { lyze the measures enclosed in a PMS should be adequate with respect to the provided information. }\end{array}$ & Economic & {$[2,5,41]$} \\
\hline \multirow{3}{*}{ 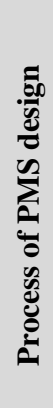 } & (R.5) & $\begin{array}{l}\text { Consideration of inter- } \\
\text { dependencies among } \\
\text { measures }\end{array}$ & $\begin{array}{l}\text { The interdependencies among the measures enclosed in the PMS should be considered during the process of } \\
\text { PMS design and consolidation. }\end{array}$ & Informational & {$[30,31,42,47,69]$} \\
\hline & (R.6) & $\begin{array}{l}\text { Consideration of } \\
\text { existing measures }\end{array}$ & $\begin{array}{l}\text { The measures enclosed in existing PMS should be considered during the process of PMS design and consoli- } \\
\text { dation. }\end{array}$ & Informational & {$[4,25,54,58,83]$} \\
\hline & (R.7) & $\begin{array}{l}\text { Systematic involvement } \\
\text { of decision makers and } \\
\text { subject matter experts }\end{array}$ & $\begin{array}{l}\text { The decision makers who will use the PMS and the company's subject matter experts in performance meas- } \\
\text { urement should be involved systematically during the process of PMS design and consolidation. }\end{array}$ & - & {$[4,14,30,47,83]$} \\
\hline
\end{tabular}

Table 1. Requirements for performance measurement systems 


\begin{tabular}{|c|c|c|c|c|c|c|c|}
\hline & \multicolumn{4}{|c|}{ PMS as design products } & \multicolumn{3}{|c|}{ Process of PMS design } \\
\hline & (R.1) & (R.2) & (R.3) & (R.4) & (R.5) & (R.6) & (R.7) \\
\hline $\begin{array}{c}\text { Bourne et al. } \\
{[10]}\end{array}$ & $\mathrm{n} / \mathrm{a}$ & $\begin{array}{l}\text { Postulated, but not } \\
\text { specified within the } \\
\text { approach }\end{array}$ & $\mathrm{n} / \mathrm{a}$ & $\mathrm{n} / \mathrm{a}$ & $\mathrm{n} / \mathrm{a}$ & $\begin{array}{l}\text { Postulated. Insights from a } \\
\text { case study that presents an } \\
\text { updated PMS }\end{array}$ & $\begin{array}{l}\text { Involving executives } \\
\text { through a workshop and } \\
\text { assistance of experts }\end{array}$ \\
\hline $\begin{array}{c}\text { Jensen and } \\
\text { Sage } \\
{[40]}\end{array}$ & $\begin{array}{c}\text { Information } \\
\text { requirements analysis } \\
\text { with continuous } \\
\text { "refinement" }\end{array}$ & $\begin{array}{c}\text { Each measure is } \\
\text { qualitatively } \\
\text { attributed to prede- } \\
\text { fined corporate objec- } \\
\text { tives. }\end{array}$ & $\mathrm{n} / \mathrm{a}$ & $\begin{array}{l}\text { Decision rule: } \\
\text { costs of reporting a } \\
\text { measure should not } \\
\text { exceed its "value" }\end{array}$ & $\mathrm{n} / \mathrm{a}$ & $\begin{array}{l}\text { "Gap analysis" that } \\
\text { compares the actual PMS } \\
\text { with a newly designed PMS } \\
\text { to reveal necessary changes }\end{array}$ & $\begin{array}{l}\text { Automated "organization- } \\
\text { al performance tracking } \\
\text { and improvement analysis } \\
\text { system" operated by } \\
\text { decision makers }\end{array}$ \\
\hline $\begin{array}{c}\text { Medori and } \\
\text { Steeple } \\
{[59]}\end{array}$ & $\mathrm{n} / \mathrm{a}$ & \begin{tabular}{|c|} 
Company success \\
factors serve as basis \\
for measure \\
definition.
\end{tabular} & $\mathrm{n} / \mathrm{a}$ & $\mathrm{n} / \mathrm{a}$ & $\mathrm{n} / \mathrm{a}$ & $\begin{array}{l}\text { "Gap analysis" that } \\
\text { compares the actual PMS } \\
\text { with a newly designed PMS } \\
\text { to reveal necessary changes }\end{array}$ & $\mathrm{n} / \mathrm{a}$ \\
\hline $\begin{array}{l}\text { Neely et al. } \\
\quad[62]\end{array}$ & $\begin{array}{c}\text { Brainstorming to } \\
\text { identify all required } \\
\text { information, including } \\
\text { comprehensiveness } \\
\text { check }\end{array}$ & $\begin{array}{l}\text { Postulated, but not } \\
\text { specified within the } \\
\text { approach }\end{array}$ & $\mathrm{n} / \mathrm{a}$ & $\begin{array}{l}\text { Cost-benefit matrix } \\
\text { of measures }\end{array}$ & $\begin{array}{l}\text { Postulated, but not } \\
\text { specified within the } \\
\text { approach }\end{array}$ & $\begin{array}{l}\text { Ongoing reviews and } \\
\text { updates by means of a } \\
\text { review checklist }\end{array}$ & $\begin{array}{c}\text { Continuous } \\
\text { involvement of } \\
\text { executives and } \\
\text { assistance of experts }\end{array}$ \\
\hline $\begin{array}{l}\text { Röglinger } \\
{[70]}\end{array}$ & $\begin{array}{l}\text { Postulated, but not } \\
\text { specified within the } \\
\text { approach }\end{array}$ & \begin{tabular}{|c|} 
Each measure is \\
qualitatively \\
attributed to prede- \\
fined success factors.
\end{tabular} & $\begin{array}{l}\text { Aims at reducing the } \\
\text { number of enclosed } \\
\text { measures }\end{array}$ & $\begin{array}{l}\text { Costs for customizing } \\
\text { and maintaining re- } \\
\text { porting tools }\end{array}$ & $\begin{array}{l}\text { Implicitly based on } \\
\text { stochastic, empirical } \\
\text { interdependencies }\end{array}$ & $\begin{array}{l}\text { Determines optimal number } \\
\text { of measures to which a cur- } \\
\text { rent PMS should be reduced }\end{array}$ & $\begin{array}{l}\text { Determination of model } \\
\text { parameters by subject } \\
\text { matter experts }\end{array}$ \\
\hline $\begin{array}{c}\text { Sousa et al. } \\
{[76]}\end{array}$ & $\mathrm{n} / \mathrm{a}$ & $\begin{array}{l}\text { Postulated, but not } \\
\text { specified within the } \\
\text { approach }\end{array}$ & $\mathrm{n} / \mathrm{a}$ & $\mathrm{n} / \mathrm{a}$ & $\begin{array}{l}\text { Identification of } \\
\text { interdependencies } \\
\text { via a systems dy- } \\
\text { namics approach } \\
\text { (case study) }\end{array}$ & $\begin{array}{l}\text { Improving the actual PMS } \\
\text { with the systems dynamics } \\
\text { approach to identifying } \\
\text { interdependencies }\end{array}$ & $\mathrm{n} / \mathrm{a}$ \\
\hline $\begin{array}{l}\text { Wouters and } \\
\text { Sportel [83] }\end{array}$ & $\begin{array}{l}\text { Postulated, but not } \\
\text { specified within the } \\
\text { approach }\end{array}$ & $\begin{array}{l}\text { Postulated, but not } \\
\text { specified within the } \\
\text { approach }\end{array}$ & $\mathrm{n} / \mathrm{a}$ & $\mathrm{n} / \mathrm{a}$ & $\mathrm{n} / \mathrm{a}$ & $\begin{array}{c}\text { Case study on the } \\
\text { development of a PMS } \\
\text { considering existing } \\
\text { measures }\end{array}$ & $\begin{array}{l}\text { Group discussions } \\
\text { and continuous } \\
\text { involvement of } \\
\text { executives }\end{array}$ \\
\hline
\end{tabular}

Table 2. An analysis of existing approaches to PMS design and consolidation 


\begin{tabular}{|c|c|c|c|}
\hline \multicolumn{2}{|r|}{ Requirement } & \multirow[b]{2}{*}{$\begin{array}{l}\text { Features of the decision framework for PMS consolidation } \\
\text { To determine the extent to which a consolidated PMS covers the decision mak- } \\
\text { ers' information requirements, we rely on the stochastic, empirical interdepend- } \\
\text { encies among enclosed and non-enclosed measures (see R.5). On the assumption } \\
\text { that all measures are thematically appropriate, each enclosed measure directly } \\
\text { contributes to covering the decision makers' information requirements. The } \\
\text { interdependencies with the non-enclosed measures at least partially compensate } \\
\text { for the missing direct contribution. The idea is that if the variation of a non- } \\
\text { enclosed measure can be explained perfectly by the enclosed measures it can be } \\
\text { omitted without loss of information. }\end{array}$} & \multirow[b]{2}{*}{$\begin{array}{l}\text { Discussion } \\
\text { Relying on stochastic, empirical interdependencies abstracts from the semantics of } \\
\text { measures. Therefore, measure-specific meta information (e.g., about whether a } \\
\text { particular measure is leading, lagging, financial, or non-financial) and weak as- } \\
\text { pects, such as the decision makers' subjective information requirements, cannot be } \\
\text { considered. One possibility to mitigate this weakness would be to check whether } \\
\text { the consolidated PMS is sufficiently balanced after the decision framework has } \\
\text { been applied. If not, measures can be added or changed based on careful delibera- } \\
\text { tion. It is important to note that those parts of the decision makers' information } \\
\text { requirements that cannot be covered by the existing measures are out of scope. If } \\
\text { necessary, novel measures from outside the existing PMS have to be integrated. }\end{array}$} \\
\hline (R.1) & $\begin{array}{l}\text { Coverage of the } \\
\text { decision makers' } \\
\text { information } \\
\text { requirements }\end{array}$ & & \\
\hline (R.2) & $\begin{array}{l}\text { Alignment with } \\
\text { corporate objec- } \\
\text { tives }\end{array}$ & $\begin{array}{l}\text { To determine the extent to which a consolidated PMS aligns with the company's } \\
\text { strategy and objectives at a corporate level, we rely on the stochastic, empirical } \\
\text { interdependencies between the measures enclosed in the consolidated PMS and } \\
\text { the top measure (see R.5). The idea is that if the variation of the top measure can } \\
\text { be explained perfectly by the enclosed measures, the consolidated PMS is fully } \\
\text { aligned with the company's strategy and objectives at a corporate level. }\end{array}$ & $\begin{array}{l}\text { We assume that the company's strategy and objective at a corporate level are } \\
\text { reflected in a single top measure. As large companies sometimes rely on multiple } \\
\text { top measures, the decision framework needs to be extended accordingly in future } \\
\text { research endeavors. }\end{array}$ \\
\hline (R.3) & $\begin{array}{l}\text { Adequate infor- } \\
\text { mation pro- } \\
\text { cessing com- } \\
\text { plexity }\end{array}$ & $\begin{array}{l}\text { To determine the information processing complexity induced by a consolidated } \\
\text { PMS, we rely on the number of enclosed measures, the individual complexity of } \\
\text { the enclosed measures, and the heterogeneity of the enclosed measures. }\end{array}$ & $\begin{array}{l}\text { The heterogeneity of a consolidated PMS only depends on the different units fea- } \\
\text { tured by enclosed measures. Moreover, measure-specific complexity is operation- } \\
\text { alized using complexity classes instead of detailed estimations. }\end{array}$ \\
\hline (R.4) & $\begin{array}{l}\text { Adequate costs } \\
\text { for operations } \\
\text { and maintenance } \\
\text { of the supporting } \\
\text { infrastructure }\end{array}$ & $\begin{array}{l}\text { The costs for operations and maintenance induced by a consolidated PMS are } \\
\text { captured by means of two cost classes: overarching costs for configuring, prepar- } \\
\text { ing, maintaining, and disseminating management reports, which depend on the } \\
\text { number of enclosed measures, and individual costs for data collection and quality } \\
\text { assessment. }\end{array}$ & $\begin{array}{l}\text { Determining valid values is a tedious task in real-world scenarios and may cause } \\
\text { an inadequate elicitation effort as well as spurious precision. We therefore rely on } \\
\text { cost classes instead of detailed estimations. }\end{array}$ \\
\hline (R.5) & $\begin{array}{l}\text { Consideration of } \\
\text { interdependencies } \\
\text { among measures }\end{array}$ & $\begin{array}{l}\text { The decision framework considers stochastic, empirical interdependencies. The } \\
\text { strength of the interdependencies is quantified by means of coefficients of deter- } \\
\text { mination as auxiliary quantities calculated via multiple linear regression. }\end{array}$ & $\begin{array}{l}\text { We assume that the interdependencies under investigation are linear in nature and } \\
\text { constant over time. To avoid dysfunctional effects, we require that each interde- } \\
\text { pendency can be interpreted and is justified by subject matter experts. }\end{array}$ \\
\hline
\end{tabular}




\begin{tabular}{|c|c|c|c|}
\hline (R.6) & $\begin{array}{l}\text { Consideration of } \\
\text { existing measures }\end{array}$ & $\begin{array}{l}\text { As the decision framework is intended for PMS consolidation, it focuses exclu- } \\
\text { sively on existing measures, i.e., on the question which subset of the existing } \\
\text { PMS should be kept or deleted based on informational and economic considera- } \\
\text { tions. Moreover, the existing PMS serves as a benchmark for operationalizing } \\
\text { (R.1) to (R.4). }\end{array}$ & $\begin{array}{l}\text { Currently, the decision framework does not consider the effects of novel measures } \\
\text { that have not yet been part of the existing PMS. One reason is that no historical } \\
\text { data exists for novel measures, so it cannot be determined whether there are any } \\
\text { meaningfully interpretable and justifiable interdependencies among existing and } \\
\text { novel measures (see R.5). Regarding (R.1), the best result achievable is that the } \\
\text { consolidated PMS provides the same information as the existing PMS. }\end{array}$ \\
\hline (R.7) & $\begin{array}{l}\text { Systematic in- } \\
\text { volvement of } \\
\text { decision makers } \\
\text { and subject mat- } \\
\text { ter experts }\end{array}$ & $\begin{array}{l}\text { Decision makers and subject matter experts are involved to justify interdepend- } \\
\text { encies and estimate the values of the input parameters. These input parameters } \\
\text { include the monetary equivalents of covering the information provided by the } \\
\text { existing PMS and perfect alignment with the objectives at a corporate level (see } \\
\text { R.1) as well as for the ability to cope with the information complexity caused by } \\
\text { the existing PMS (see R.2). Other input parameters are the mapping of existing } \\
\text { measures to complexity classes, which is required for determining the corre- } \\
\text { sponding information processing complexity (see R.3), and cost classes required } \\
\text { for determining the cost for operations and maintenance (see R.4). }\end{array}$ & $\begin{array}{l}\text { All these parameters help express the relative importance of the objective func- } \\
\text { tion's components. Due to the decision framework's quantitative nature, it can be } \\
\text { traced how modifying each parameter influences the outcome of PMS consolida- } \\
\text { tion. It would be a mistake to believe that the decision framework leads to objec- } \\
\text { tive and truly optimal decisions in industry. One reason for this is that estimating } \\
\text { the parameters' values is beset with subjective influences-we even require the } \\
\text { decision makers to indicate subjective values. Another reason is that the stochastic, } \\
\text { empirical interdependencies may be subject to data quality problems or lagging } \\
\text { effects that have to be separated and eliminated beforehand. }\end{array}$ \\
\hline
\end{tabular}

Table 3. Evaluating the decision framework for PMS consolidation against the requirements of PMS (feature comparison) 


\begin{tabular}{|l|c|}
\hline \multicolumn{1}{|c|}{ Overarching Parameter } & Value \\
\hline $\begin{array}{l}\text { Business unit-specific weighting } \\
\text { factor ( }(\mathrm{O})\end{array}$ & 0.8 \\
\hline $\begin{array}{l}\text { Monetary equivalent of all in- } \\
\text { formation provided by } M \text { and } \\
\text { perfect alignment with the top } \\
\text { measure }(I)\end{array}$ & $\begin{array}{c}1,200,000 \\
\text { EUR }\end{array}$ \\
\hline $\begin{array}{l}\text { Monetary equivalent of coping } \\
\text { with information processing } \\
\text { complexity }(S)\end{array}$ & $\begin{array}{c}200,000 \\
\text { EUR }\end{array}$ \\
\hline $\begin{array}{l}\text { Overall costs for management } \\
\text { reports }\left(C_{M}\right)\end{array}$ & 100,000 \\
\hline
\end{tabular}

\begin{tabular}{|c|c|c|c|}
\hline Measure & $\begin{array}{c}\text { Complexity* } \\
\left(\boldsymbol{e}_{\boldsymbol{i}}\right)\end{array}$ & $\begin{array}{c}\text { Cost level** } \\
\left(\boldsymbol{c}_{\boldsymbol{i}}\right)\end{array}$ & Unit $\left(\boldsymbol{u}_{\boldsymbol{i}}\right)$ \\
\hline $\mathrm{SC}_{1}$ & 4 & $10,000 \mathrm{EUR}$ & {$[\%]$} \\
\hline $\mathrm{SC}_{2}$ & 3 & $10,000 \mathrm{EUR}$ & {$[\%]$} \\
\hline $\mathrm{SC}_{3}$ & 3 & $15,000 \mathrm{EUR}$ & {$[\%]$} \\
\hline $\mathrm{SC}_{4}$ & 3 & $15,000 \mathrm{EUR}$ & {$[$ [Days] } \\
\hline $\mathrm{SC}_{5}$ & 3 & $5,000 \mathrm{EUR}$ & {$[$ Days] } \\
\hline $\mathrm{LC}_{1}$ & 5 & $15,000 \mathrm{EUR}$ & {$[\%]$} \\
\hline $\mathrm{LC}_{2}$ & 2 & $15,000 \mathrm{EUR}$ & {$[\%]$} \\
\hline $\mathrm{YQ}_{1}$ & 2 & $15,000 \mathrm{EUR}$ & {$[\%]$} \\
\hline $\mathrm{YQ}_{2}$ & 4 & $15,000 \mathrm{EUR}$ & {$[\mathrm{EUR}]$} \\
\hline $\mathrm{YQ}_{3}$ & 2 & $10,000 \mathrm{EUR}$ & {$[$ Amount] } \\
\hline
\end{tabular}

Table 4. Input parameters 
Laura Großwiele is research assistant at the FIM Research Center Finance \& Information Management at the University of Augsburg (Germany). She holds a diploma in business administration. Besides decision support systems, her research interests include business intelligence, IT performance management, and risk/return management.

Maximilian Röglinger is post-doctoral fellow with the FIM Research Center Finance \& Information Management at the University of Augsburg, Germany, where he heads the research groups on valuebased business process management and customer relationship management. In 2011, Maximilian was appointed Interim Associate Professor for Information Systems. His research has been published in journals like Business \& Information Systems Engineering, Business Process Management Journal, Journal of the Association for Information Systems, Journal of Business Economics, and Journal of Strategic Information Systems. Maximilian is engaged in various applied research projects with industry partners. Maximilian earned his $\mathrm{PhD}$ in Information Systems at the University of Augsburg and holds a Diploma from the University of Bamberg, Germany. His research interests include business intelligence, business process decision making, and process industrialization.

Bettina Friedl was research assistant at the FIM Research Center Finance \& Information Management at the University of Augsburg (Germany). Since 2011, she has been working for Karl Zeiss in Germany. Bettina holds a diploma in mathematics and a PhD in Information Systems. Her research has been published in journals like Business \& Information Systems Engineering, Journal of Banking and Financial Research and Journal of Management Control as well as presented at various international conferences. Bettina's research interests include decision support systems, online social networks, risk/return management, and service-oriented architectures. 